Sarah Cooper and Owen D Thomas (Forthcoming) Understanding Issue Salience and the (Non) Appointment of UK Public Inquiries: A New Research Agenda, Public Money \& Management.

Accepted for publication by Public Money \& Management on $16^{\text {th }}$ June 2019. This is a pre-print, accepted manuscript. This is not the copy-edited or published article, which will differ from this version. Please cite the published version.

Corresponding author: Dr Owen D Thomas, Senior Lecturer in Politics and International Relations, University of Exeter, UK. Email: o.d.thomas@exeter.ac.uk 


\title{
Understanding Issue Salience and the (Non) Appointment of UK Public Inquiries: A New Research Agenda
}

\author{
Dr Owen Thomas, University of Exeter, UK, o.d.thomas@exeter.ac.uk \\ Dr Sarah Cooper, University of Exeter, UK, s.g.l.cooper@exeter.ac.uk
}

\section{Impact Statement}

Why are inquiries appointed and what factors are influential? Research shows that inquiry appointment is driven by issue salience, but how this occurs is unclear. We suggest that issue salience is driven by victim relatability, visibility of failings and perceived blameworthiness. This has significant implications: some investigations may be appointed in an inappropriate form to effectively address inequality: wrongdoing against minorities may not be sufficiently relatable to drive inquiry appointment, and inquiries into blameworthy behaviour may overlook complex systemic flaws.

Successive UK institutions have been embroiled in crisis. Sometimes these result in apologies and resignations (as occurred in the recent Windrush scandal). Other times, crises lead to inquiries (such as the ongoing Grenfell Tower and child sexual abuse inquiries). Presented as independent and publicly accessible interventions for fact-finding and lesson learning, inquiries proffer reassurance that 'something is being done' and can catalyse legislative change - though their ability to deliver on these promises is debated (inter alia Brown, 2003; Elliott, 2009; Stark, 2018). The process of politicisation whereby policy failures become crisis has received significant attention (inter alia Brändström and Kuipers, 2003; Boin et al., 2008; Howlett, 2012). But research on inquiry appointment - that is, how crises become inquiries - is limited to a sole study suggesting that appointment is determined by blame avoidance, government popularity and issue salience with the latter posited as the most powerful (Sulitzeanu-Kenan, 2010). How an issue becomes salient as deserving of inquiry, however, remains vague. This paper suggests three potential causal mechanisms that rest between cause and effect, and we encourage a new research agenda to chart this causal inference.

Using a 'typical' case study selection, we examine three institutional crises that were addressed through varying inquiry types: a full statutory inquiry into press ethics (the Leveson Inquiry, 2011); a non-statutory inquiry into care at Mid-Staffordshire NHS Foundation Trust (2010); and the 
inquest following the death of Ian Tomlinson (2011). We argue that salience in these cases was affected by three mechanisms: the relatability of victims, the visibility of systemic failings, and perceived blameworthiness behaviour. These cases suggest that when all three coalesce, the appointment of a full public inquiry is more likely. We do not make a claim of generalisable causality; rather this paper is significant as a modest first step in building a theoretical account of the mechanisms of salience.

This framework has two important implications for widespread social inequality. First, greater salience is associated in the case studies with the presence of relatable victims, but this relatability in turn is shaped by public empathy rather than the degree of harm suffered. Accordingly, where there is a lack of sympathy for wrongdoing experienced by minorities, inquiry appointment is less likely and risk of chronic policy failure is high. Secondly, systemic flaws are unlikely to be publicly salient unless they fit a methodologically individualist frame of blameworthiness whereby wrongdoing is perceived to be intentional or avoidable - i.e. actors knew or should have known that their behaviour was wrong (Veitch, 2007: 85-92). Social inequalities (such as those caused by ingrained culture) that are not easily reducible to knowing, reckless or negligent behaviour are unlikely to be salient and are more likely treated as quasi-fatalist tragedies. Inequalities that do fit this frame may be investigated through a statutory inquiry, but this may be ill-suited to address the issue if the roots are not primarily reducible to individualist causes. These issues may be better addressed by other forms of independent ad hoc investigatory tools - such as Royal Commissions or independent panels. In sum, the dynamics of public salience may lead the appointment of inappropriate inquiry types to address institutional crises.

The paper is organised as follows. Scoping the inquiry literature, we sketch a theoretical framework to unpack the dimensions of issue salience. We then outline our methodology and case study selection before analysing three institutional crises, in turn extrapolating a list of the three casual mechanisms. Finally, we develop the implications for social inequality against two rising issues: police handling of complaints of sexual assault and social housing following the Grenfell Tower disaster, proving important empirical impetus for further study in this area.

\section{Inquiries: what we think we know}

Public inquiries are appointed in the wake of a crisis (Burgess 2011). They are institutions of last resort, instigated when there is widespread suspicion that relevant state authorities lack the requisite powers and independence necessary to investigate or that, worse still, those authorities may be complicit in the alleged wrongdoing (Scraton, 2004). In order to resolve such crises, inquiries are expected to achieve some or all of the following functions: 
- establish the facts and causes of what happened;

- learn lessons to prevent recurrences;

- facilitate public catharsis that could enable reconciliation;

- rebuild public trust by providing a reassurance that the issues have been properly investigated;

- hold actors and institutions to account;

- allow government to demonstrate that 'something is being done' (Howe 1999 summarised in Walshe and Higgins, 2002).

While acknowledging the debate as to whether inquiries are "placebo or panacea" (Elliott and McGuiness, 2002), our starting point is that inquiries can be effective tools of accountability and learning (Stark 2018). The term 'public inquiry' is imprecise, but following Sulitzeanu-Kenan (2006: 624) we define the tool as:

- an ad hoc institution, dissolved once its task is concluded;

- independent of the executive;

- established by a government minister;

- a discretionary appointment that is not generated by statutes or other rules (such as legally mandated inquests);

- appointed to investigate a discrete event;

- concerned with the past;

- allows public scrutiny of the facts.

We distinguish three categories of real-life inquiries that meet this definition to varying degrees: statutory inquiries; non-statutory ad hoc independent investigations; and investigations conducted by permanent governmental or judicial bodies. All three types have advantages and disadvantages in fulfilling the functions above.

Statutory inquiries have powers (e.g. Inquiries Act 2005) to take evidence under oath and compel the production of witnesses and evidence. Examples include the Independent Inquiry into Child Sexual Abuse (2014-) and the Baha Mouse Inquiry (2008-2011). This juridical style of inquiry is regarded as the 'gold standard' of investigation, based on a perception of the legal method as the most rigorous and objective means of determining facts (Walshe and Higgins, 2002: 899; Public Administration Select Committee, 2005: 41). Statutory inquiries are also legally obligated to ensure that the public are able to watch the inquiry and view evidence. This performance of rule-based 
liberal democracy offers some symbolic reassurance of "an open, transparent society where, if a disaster arises, the voices of the powerless are not ignored and the powerful are held to account" (Burgess, 2011: 7). The forensic style of juridical cross-examination is well-suited to investigate fine-grained behaviour in a discrete event (e.g. the Baha Mousa Inquiry's tracing of behaviour British soldiers in Iraq) but less capable of addressing complex sociological and structural pathologies (Thomas 2017). Statutory inquiries are also lengthy and expensive.

There are several forms of ad-hoc independent investigations that can only be established by government ministers. Non-statutory inquiries lack legal powers and rely on the cooperation of those involved. They are also not required to hold public hearings (though many do). They can facilitate a more inquisitorial, less adversarial approach, and enable sensitive evidence to be given in camera (Cabinet Office, 2012: 3). For instance, the Iraq 'Chilcot' Inquiry (2009-2016) was conduct by a committee of privy counsellors including former civil servants, a retired diplomat and two scholars. Independent panels work in private to gather and disclose information via a report and do not hold public hearings (e.g. Hillsborough and Gosport). Royal Commissions, which have fallen into disuse in the UK, focus on a broad policy area rather than a discrete event (such as the Royal Commission on Reform of the House of Lords). Both independent panels and Royal Commissions may have advantages over statutory inquiries when the crisis would benefit from the establishment of a historical account or the examination of broad policy challenges not connected to a specific event (Norris and Shepheard, 2017:12).

Investigatory tools by permanent bodies are not ad hoc or necessarily established by a government minister. Although investigating past events, they are not required to hold public hearings or publish evidence. Inquests, for instance, are legally mandated following an unexplained or unnatural death (e.g. the inquests into the deaths of four soldiers at Deepcut barracks). Similarly, the Department of Transport has several accident investigation branches legally mandated to investigate serious transport incidents. Whilst quick and cheap, such investigations can only examine the circumstances strictly related to the immediate causes of death; scrutiny of broader concerns requires the appointment of another tool (e.g. when the inquest into the death of Alexander Litvinenko was converted into a statutory inquiry to investigate the role of the Russian state).

\section{Why are inquiries appointed? Dimensions of salience}

The frequency of inquiries has increased significantly since the 1990s (Norris and Shepheard, 2017: 9), reflecting a broadening of public outrage into areas of 'social risk' such as child abuse and 
medical malpractice (Burgess, 2011:4). Nevertheless, relatively little attention has been afforded to why governments appoint inquiries into some events and not others. A sole explanation is provided by Sulitzeanu-Kenan (2010) who, drawing on blame avoidance theory, argues that the decision to appoint is perceived by ministers as a short-term cost of acknowledging that something has gone wrong. Once this short-term cost is paid, an inquiry becomes a venue-shifting strategy that allows governments and ministers to refrain from addressing the issue for as long as the investigation continues - which could last years. However, the more likely it is that blame will be allocated near to the appointing officeholder, the less likely it is an inquiry will be appointed. This is because the act of appointing an inquiry explicitly acknowledges the existence of a problem, and thereby reduces the potential for other political strategies including denial, concealment, or reframing. Sulitzeanu-Kenan also identifies a conditional positive relationship between electoral support and the propensity to appoint: popular governments are more likely to do so because they can bear the cost of loss acknowledgement and, potentially, blame, in the report. Yet regardless of whether governmental blame is attributed, if substantial public pressure for the appointment of a public inquiry exists, the cost of non-appointment outweighs the benefits of blame avoidance. Ultimately, Sulitzeanu-Kenan claims that once calls for a public inquiry reach a threshold level of salience, appointment becomes the path of least resistance.

One question remains unaddressed: why do some controversial issues or events become media salient as needing an inquiry, and some do not? The mechanisms of politicisation that effect how a failure becomes salience as a 'crisis' have been widely discussed in the literature (Brändström and Kuipers, 2003; Boin et al., 2008; Howlett, 2012). Whereas much of the focus has been on how failures become crises, our concern is how crises that already have a significant degree of salience become inquiries. Nonetheless, this literature suggests some helpful lines of inquiry for unpacking salience.

A first area concerns public attitudes toward the persons shouldering the burden of the policy failure: the presence of relatable victims is an essential precondition for a failure to be perceived as a violation of core public values (Brändström and Kuipers, 2003: 290) A second concern hinges on whether a policy failure is perceived to an isolated one-off incident or a symptom of a wider systemic failure that implies flaws in professional culture, standards, operating procedures and policies that inform the delivery of services everywhere (Bovens and t'Hart, 1996; Brändström and Kuipers, 2003: 295; Howlett, 2012: 543). A third concern relates to the blameworthiness of the individuals, groups and institutions implicated in the failure. Two key constituents of 
blameworthiness are intentionality and avoidability (Hood, 2010). In the former, a distinction can be drawn between failures caused by intentional wrongdoing and failures that occurred despite good intentions (Howlett, 2012: 544, see also Roots 2004). In the latter, a policy failure that occurred without ill-will can nonetheless be considered avoidable (or predictable) if those individuals should have known better (e.g. through recklessness or negligence) (Thomas, 2017). These three lines of inquiry are summarised below.

Table 1 Dimensions of Issue Salience

\begin{tabular}{|c|c|c|}
\hline Dimension & Salience & Indicator \\
\hline \multirow{2}{*}{$\begin{array}{l}\text { How relatable is the } \\
\text { victim(s)? }\end{array}$} & High & $\begin{array}{l}\text { - Affects a majority } \\
\text { - Victim not responsible }\end{array}$ \\
\hline & Low & $\begin{array}{l}\text { - Affects a minority } \\
\text { - Victim shares responsibility }\end{array}$ \\
\hline \multirow{2}{*}{$\begin{array}{l}\text { What is the perceived } \\
\text { extent of the failing? }\end{array}$} & High & - Widespread systemic failing \\
\hline & Low & - One-off, isolated failing \\
\hline \multirow{2}{*}{$\begin{array}{l}\text { How is blameworthiness } \\
\text { perceived? }\end{array}$} & High & $\begin{array}{l}\text { - Intentional wrongdoing by institution } \\
\text { and/or leading figures } \\
\text { - Avoidable wrongdoing: reckless or } \\
\text { negligent behaviour }\end{array}$ \\
\hline & Low & $\begin{array}{l}\text { - Unavoidable, honest mistakes } \\
\text { - Institution deceived by 'bad apples' } \\
\text { - Inevitable overspill of an organisation }\end{array}$ \\
\hline
\end{tabular}

\section{Methodology}

Our intention is to encourage new research into the mechanisms that lie between the causes and effect of inquiry appointment - as part of a wider drive to address the lack of comparative, generalisable evidence about inquiries (Stark, 2018). We use a small number of case studies that can offer inferences for the wider pool of institutional crises and inquiries in the UK. Using the dimensions of issue salience above as a toolkit to explore initial ideas of causality, we use case studies that are 'typical' examples of our inquiry types of interest: a statutory inquiry, a nonstatutory inquiry (part of the 'ad-hoc independent investigation' type), and an inquest (part of the 'investigation by permanent bodies' type). In this paper, we understand causality as qualitative exploration of the 'causal mechanisms' existing between issue salience as the cause and public inquiry as the effect (King, Keohane and Verba 1994). The selection of the unit of study is 
underpinned by two methodological principles. First, they demonstrate a stable cross-case relationship between the independent variable (issue salience) and the dependent variable (inquiry type). Second, and in deference to the 'heroic' claims of Seawright and Gerring (2008), they are instances of notoriety that can credibly represent a larger pool of cases. This latter aspect is of critical importance to our study given the existing appreciation that is already afforded to media salience. We suggest a causal narrative account that evaluates the relatable victim(s), visible systemic failings, and perceived blameworthy behaviour within the statutory Leveson Inquiry (2011), the non-statutory inquiry into Mid-Staffordshire NHS Trust (2010), and the inquests and criminal prosecution following the death of Ian Tomlinson in 2011.

\section{Case Studies}

\section{The Leveson Inquiry}

On 4 July 2011, it was revealed that a private investigator working for the News of the World (NotW) newspaper had hacked into the mobile phone voicemail of the murdered teenager, Milly Dowler. The hacking, which took place in 2000 , led the newspaper to publish false leads and, by deleting some messages, gave the Dowler family false hope that Milly might still be alive. Within days the revelation, the Prime Minister appointed a full statutory inquiry, describing a widespread multiinstitutional crisis. "The whole country has been shocked", David Cameron claimed, "by disgraceful accusations of widespread lawbreaking...corruption by some police officers... [the] failure of our political system over many, many years to tackle [the] problem" (Cameron cited in Leveson, 2012: 3). This was a crisis waiting to happen (Brock, 2012). The hacking of Dowler's phone was symptomatic of a wider pathological relationship between the press, the public, the police and the political class.

The 'phone hacking scandal' did not achieve a coherent level of media salience for many years. Since the early 2000s, unlawful behaviour by members of the press had been blamed on individual bad apples rather than system failings or widespread culture problems. For instance, Operation Motorman, in 2003, revealed a network of journalists (from several different newspapers), private investigators, police officers and civil servants engaged in the illegal trade of personal formation. Only two private detectives, a retired police officer and a civil servant received conditional discharges. In 2006, Clive Goodman, a journalist employed by NotW, and Glenn Mulcaire, a private detective, received custodial prison sentences after pleading guilty to illegally hacking into 
the voicemail messages of members of the Royal Household. News International - the owner of NotW - blamed the hacking on the actions of 'rogue reporters' even though the presiding judge of Goodman's trial was explicit that other members of staff would have been aware (Culture, Media and Sport Committee, 2010). In both cases, no wider investigation of the knowledge and involvement of others at NotW or elsewhere took place. In the years that followed, both the Guardian and New York Times published investigations claiming that phone hacking was undertaken at NotW on a far greater scale (Daoust, 2011; Natta, Becker and Bowley, 2010). Despite this, the Metropolitan Police Service (MPS) controversially decided not to reopen their investigation. The Press Complaints Commission (PCC) - the self-appointed regulatory body for British newspapers whose membership and funding was controlled severing editors and industry figures - publicly condemned the Guardian's investigation in a report that has since been withdrawn (Leveson, 2012: $8)$.

Regardless of the cause, some of the victims of phone hacking and other egregious intrusion were salient as everyday, blameless people. The revelation of Dowler's phone hacking was a moment of puncture, providing irrefutable proof that the hacking was not limited to celebrities, politicians or royals, but included 'ordinary' members of the public (Hopkins, 2012:9). The victims included people who found themselves in the public eye due to tragic circumstances beyond their control, such as Kate McCann (the mother of Madeleine, abducted in Portugal) whose private diaries were published by $N o t W$ without her consent.

The 'rogue reporter' narrative was also disrupted following civil litigation by the actor Sienna Miller, which revealed that senior staff at $N o t W$ were complicit in phone hacking. The visibility of systemic failings grew as it became clear that senior figures within News International, the PCC (that had dismissed any need to investigate the industry), and the MPS (that had refused to reopen a criminal investigation these organisations) would have, or should have known, that there was a wider "culture" of condoning and even encouraging investigative methods that violated basic privacy rights (Culture, Media and Sport Committee, 2012). Following an internal investigation, News International - the parent company and publisher of NotW - referred itself to the MPS, who reopened the investigation. At the time that the Leveson inquiry was appointed, the investigation had identified 3,870 potential victims. The inquiry would subsequently hear evidence that newsroom culture put pressure on journalists to forgo ethical concerns for fear of losing employment. One newspaper owner (Desmond, 2012) simply told the inquiry 'Ethical, I don't know what the word means... We do not talk about ethics or morals'. 
Robert Francis Inquiry report into Mid-Staffordshire NHS Foundation Trust

In 2008, the Mid-Staffordshire Healthcare Trust was placed under investigation by the Healthcare Commission after failing to provide a robust explanation for a higher than expected Hospital Standardised Mortality Ratio (Healthcare Commission 2009). Four further reviews of the foundation trust were subsequently undertaken (Alberti 2009; David Colin Thombé Report 2009, Francis 2010, Francis 2013) but it is the non-statutory inquiry, reporting in 2010 and led by Sir Robert Francis QC, that is our focus. Specifically, our attention is drawn to why this instrument was selected in preference to a full, statutory form, particularly in light that this judicial element was in fact latterly commissioned in 2013.

Turning attention first to the catalyst of 'relatable victim', the plight of Julie Bailey, the daughter of 86-year-old patient Bella Baily who died following an eight-week stay at Stafford Hospital, became a stable feature in the press. A former social worker specializing in elderly care, Julie was able to identify the low level of care experienced on the wards on numerous nights that she spent with her mother and additionally could explain these failings to the wider public. Founding 'Cure the NHS' in 2007 from a cafe in Stafford (Cure the NHS 2018), Bailey received a CBE for her advocacy for the elderly in 2014 and was undeniably a key trigger for the eventual establishment of the judicial inquiry. But this was not always the public perception that accompanied her actions. During the push for statutory action, she was often framed in negative terms across social media (Gander 2014), particularly in the local area due to the subsequent reductions to services at Stafford Hospital (Templeton 2009).

Conversely, visibility of systemic management failings was high. Alarming mortality rates at Stafford Hospital could clearly be causally linked to poor levels of care and hygiene. Popular blame for this was placed at the door of those 'at the top'. A narrative account of this wrongdoing in terms of managers chasing trust status for the hospital formed a digestible paradigm for the public (Sawer 2009). The suspension of the chief executive of the trust, Martin Yeates, in March 2008 formed a solid placatory measure. His later resignation in 2009, 3 days prior to the reporting of the 2009 Healthcare Commission review, made sense to the public and was accompanied by the stepping down of Chairman Tony Brisban. This was further bolstered by heavy criticism of the Chief Executive of the Care Quality Commission (CQC) Cynthia Bower, who formerly headed the West Midlands Strategic Healthcare Authority that oversaw Stafford Hospital in 2006-2008. The actions of perpetrators of wrongdoing had been explained, but more importantly had faced sanction and mimicked a judicial process. The need for further statutory measures in 2009 was 
therefore low, with internal review structures publicly appearing capable of addressing the issue. Here we can thus detract insights for the causal consequences of the identification of failings with the necessary inquiry type in such circumstances unlikely to be perceived in terms of a judicial intervention, with a perpetrator already highlighted and punished.

In the years that have followed, much attention has been paid to fostering safe avenues for healthcare employees of all ranks to express concerns about working conditions and the experience of patients. Largely understood and discussed as of fear of coming forward in 2013, the full statutory inquiry provided accompanying recommendations to remove constraints on whistleblowing in the NHS (Francis 2013). Helene Donnelly, in particular, raised in excess of 100 complaints about the treatment of patients and later revealed the endemic bullying that existed over falsifying documents (Calkin 2011). Appreciation of this complex organisational culture, however, has taken time to mature, and lacked public legibility in 2009. At the time, isolated blame was placed on managers chasing performance targets, and any broader problems emanating from the healthcare trust were more readily understood within the framework of 'honest mistakes' made in a public sector under pressure (Smith 2009). Despite the efforts of campaigners such as Bailey calling for a full statutory review to compel witnesseses to give evidence, the wider public largely accepted a hierarchical causality that demanded accountability from the managers, but partially accepted the inevitability of such problems when consideration was afforded to the tight resources faced by the NHS. Consequently, the perception of institutional blameworthiness at Stafford Hospital was initially low.

\section{The Ian Tomlinson Inquest}

Ian Tomlinson was a 47-year-old newspaper vendor who, on 1st April 2009, collapsed and died after walking through a public protest against the G20 summit in London. An initial statement by the MPS explained that officers had been attempting to offer medical assistance when they were attacked by protesters. This account was challenged when images emerged showing a police officer striking and pushing Tomlinson immediately prior to his collapse. The Independent Police Complaints Commission (IPCC) passed the case to the Criminal Prosecution Service (CPS) who, after a lengthy delay, announced in July 2010 that there was no realistic prospect of pursuing a conviction against the police officer. The CPS blamed the decision on contradictions between the Home Office pathologist that first examined Tomlinson and two other pathologists. The Home Office pathologist, Freddy Patel, ruled that Tomlinson died from a heart attack, while two other 
pathologists concluded that death was a result of internal bleeding caused by a blow to the abdomen. As a result, the CPS would not be able to link the assault with Tomlinson's death beyond reasonable doubt. The decision was highly controversial. The Attorney General described the decision to the House of Commons as 'profoundly unacceptable' (HC Deb 26 July 2010, c720), while a representative of Tomlinson's family described it as 'a cover-up from the start' (Bentham, 2010).

In the months after his death, Tomlinson had been framed by the media as a victim of both police violence and systemic, institutional failure. In September 2009, the CPS charged another police officer with assault upon a participant during a vigil held for Tomlinson. The officer was found not guilty after the judge accepted the officer's claim that he mistook a carton of orange juice and a digital camera carried by the victim for weapons (O’Neill, 2010). The ruling was a setback for the IPCC and CPS who, despite numerous investigations, had failed to secure disciplinary action or criminal conviction against any officer. In November, Her Majesty's Inspectorate of Constabulary published a report warning that the use of paramilitary tactics for public order policing was leading to a breakdown in public trust (HMIC, 2009). In April 2010 the MPS agreed to release an internal report relating to the death of Blair Peach - who died during an anti-Nazi protest in London in 1979, allegedly after being beaten by a police officer. The report confirmed that the officer had struck Peach and that other officers had lied about the incident to cover it up (Lewis, 2010). The CPS stated that it was unlikely the new evidence would lead to a prosecution. As Greer and McLaughlin (2011: 281) have shown, the media noted that "now, as then, where police violence resulted in death or serious injury to a member of the public, it was impossible to bring criminal charges against officers"; Tomlinson became a "prototypical example of institutional failure in which the MPS, CPS and IPCC were all implicated". At this stage, Tomlinson's death appeared to indicate a high level of victim salience, visible systemic failings, and institutional blameworthiness that could not be resolved through existing investigatory mechanisms - precisely because it was those mechanisms that were under suspicion.

The IPCC passed its report to the coroner so that an inquest could be held. Through the course of the inquest, the narrative of systemic failure and institutional blameworthiness was interrupted. During the inquest, the evidence of the pathologists was tested under questioning. Patel's conclusion that Tomlinson died of a heart attack was contradicted by three other pathologists all of whom concluded that death was caused by internal bleeding in the abdomen. (At the time, Patel was suspended by the GMC for gross misconduct in three other post-mortem examinations.) The 
jury concluded that Tomlinson had been unlawfully killed, and that "excessive and unreasonable" force had been used by the police officer against Tomlinson who "posed no threat" (Lewis, 2011).

The CPS subsequently announced that Harwood had been charged with manslaughter. During the trial, Harwood's defence relied heavily on evidence that Tomlinson was in poor health - suffering liver and brain disease caused by alcohol abuse. Harwood told the jury that he was "sorry I got it wrong", that he did not realise Tomlinson was in poor health and that if he knew that Tomlinson was an infirm alcoholic trying to get home rather than a potentially violent protester he "would not have gone anywhere near him" (Walker, 2012). After four days of deliberation, the jury found him not guilty. Harwood was dismissed from the police service following an IPCC public hearing (the first time such a hearing had been held in public) which found him guilty of gross misconduct.

Responsibility for the harm was restricted to the culpability of Patel and Harwood who, in different ways, committed gross professional misconduct. Harwood's trial and subsequent dismissal provided some validation for the integrity of the IPCC and CPS, and deflected suggestions of systemic failings. Suggestions of institutional blameworthiness were nullified by the apportioning of blame to the two 'bad apples' of Patel and Harwood.

\section{Toward a set of causal mechanisms}

Based on these case studies, we are able to propose three mechanisms for Sulitzeanu-Kenan's claim that issue salience is a causative political factor in the decision to establish a commission of inquiry. Only in one case study, when all three dimensions of salience were high, was a statutory inquiry appointed. In the two remaining case studies, the appointment of other inquiry types coincided with lower degrees of salience in some dimensions.

\section{Appointment of a statutory inquiry occurs when the victim is widely relatable}

All the victims in the case studies were highly relatable and considered blameless for the injuries and injustices that were suffered. Victims such as Kate McCann, Bella Bailey and Ian Tomlinson all garnered public empathy - and this empathy was not necessarily or solely driven by the degree of harm suffered but because their experiences could have been felt by a significant proportion of the public: unlawful media intrusion without wishing to be in the public eye, poor standards of care within the NHS, excessive police force experienced when acting entirely lawfully. The 
presence of a relatable victim appears to be a necessary precondition for the appointment of any inquiry type.

Appointment of a statutory inquiry occurs when the cause of the failing is perceived to be systemic

The case studies reflect the expectation of the literature that inquiries are appointed in the wake of a perceived crisis (Burgess, 2011). The case studies suggest that a statutory inquiry coincides with a crisis that is considered to be more than a stand-alone, ad-hoc failure - rather a symptom of a much wider policy failure. The Leveson Inquiry was announced by the Prime Minister as a response to a widespread and long-standing failure of the press and politicians. Similarly, isolated deaths at the Mid-Staffordshire Healthcare Trust were easily linked to systemic failings in care and hygiene driven by wider public sector pressures. By contrast, calls for an inquiry for Tomlinson's death were diminished by professional misconduct charges brought against Patel and Harwood suggesting one-off failures and the reassertion of good professional standards.

Appointment of a statutory inquiry occurs when institutions demonstrate a culture of blameworthy behaviour (intentional, reckless or negligent) that is irreducible to lone actors

Such blameworthy actors were only highly salient in one of the case studies: the phone hacking scandal. Our analysis suggests that one of the mechanisms for a statutory inquiry is the legibility of a pathological organisational culture that permits agents to commit acts that they knew, or should have known would be wrong. This is clearly evident in the political representation of phone hacking as attributable to a culture that condoned and encouraged actors to intentionally and knowingly commit corrupt and illegal activities. The connections between culpability and statutory inquiry appointment is logical given that statutory inquiries are often highly regarded precisely because of the employed legalistic, adversarial methods that provide a narrative of the crisis based on forensic analysis of what individuals knew or should have known about their contribution to the failing. A pathological culture is less likely to be salient when its blame cannot easily be attributed into this frame of knowing, reckless or negligent culture. When this happens, wrongdoing is often excused as an honest mistake generated by a difficult external environment or a lack of training as occurred in relation to the Mid-Staff inquiry - or as the result of 'bad apples' that operated alone the Home Office and MPS.

Table 2 Summary of case studies 


\begin{tabular}{|c|c|c|c|c|}
\hline & Relatable Victim (s) & Visible failing & $\begin{array}{l}\text { Perceived } \\
\text { blameworthiness }\end{array}$ \\
\hline \multirow{3}{*}{ 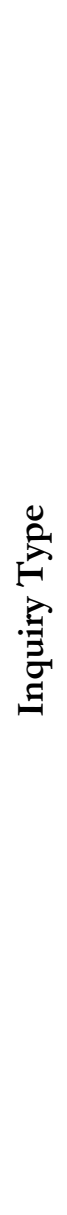 } & $\begin{array}{l}\text { Statutory } \\
\text { inquiry } \\
\text { Phone hacking } \\
\text { and Press } \\
\text { Ethics }\end{array}$ & $\begin{array}{l}\text { High: } \\
\text { Victims in the public } \\
\text { eye due to tragic } \\
\text { events: e.g. the } \\
\text { Dowler and McCann } \\
\text { families }\end{array}$ & $\begin{array}{l}\text { High: } \\
\text { Senior NotW executives } \\
\text { implicated in phone } \\
\text { hacking } \\
\text { Failure to reopen police } \\
\text { investigation by MPS } \\
\text { Assistant Commissioner } \\
\text { John Yates }\end{array}$ & $\begin{array}{l}\text { High: } \\
\text { A cultural acceptance of } \\
\text { unethical journalistic } \\
\text { practices }\end{array}$ \\
\hline & $\begin{array}{l}\text { Non- } \\
\text { statutory } \\
\text { inquiry } \\
\text { Mid- } \\
\text { Staffordshire } \\
\text { Healthcare } \\
\text { Trust }\end{array}$ & $\begin{array}{l}\text { High: } \\
\text { 86-year-old Bella } \\
\text { Bailey representative } \\
\text { of the story of many } \\
\text { (despite daughter Julie } \\
\text { Bailey seen as } \\
\text { 'whistleblower') }\end{array}$ & $\begin{array}{l}\text { High: } \\
\text { Trust's Chief Executive } \\
\text { suspended, Chairman } \\
\text { resigned } \\
\text { CQC Chief Executive } \\
\text { heavily criticised }\end{array}$ & $\begin{array}{l}\text { Low: } \\
\text { Viewed in logistical terms; } \\
\text { an NHS under pressure }\end{array}$ \\
\hline & $\begin{array}{l}\text { Permanent } \\
\text { bodies } \\
\text { (inquest, } \\
\text { professional } \\
\text { misconduct } \\
\text { and criminal } \\
\text { prosecutions) } \\
\text { Death of Ian } \\
\text { Tomlinson }\end{array}$ & $\begin{array}{l}\text { High } \\
\text { Tomlinson, an } \\
\text { innocent victim of } \\
\text { police tactics that } \\
\text { 'posed no threat'. }\end{array}$ & $\begin{array}{l}\text { High then low: } \\
\text { Suspect systemic issues } \\
\text { with MPS tactics, } \\
\text { diminished by IPCC gross } \\
\text { misconduct hearings } \\
\text { Criticism of CPS for } \\
\text { failure to prosecute, } \\
\text { diminished by trial of } \\
\text { Harwood. }\end{array}$ & $\begin{array}{l}\text { High then low: } \\
\text { Initially a 'cover-up' and } \\
\text { culture of impunity. } \\
\text { Subsequently reduced } \\
\text { through blame attribution } \\
\text { to 'bad apple' pathologist } \\
\text { and police officer }\end{array}$ \\
\hline
\end{tabular}

\section{Public Sector Implications}

The scrutiny of minority issues is limited because the identification of victims is more significantly associated with public empathy, rather than the degree of harm suffered

This creates a threshold for the initiation of any inquiry type and disproportionately restricts minority issues along two dimensions. We can intuitively assume that the public sector harbours moments of wrongdoing, or indications of future policy failure, that have not yet surpassed this benchmark. Although thresholds of problematic behaviour are an inevitable and necessary condition for action, our research suggests that a 'big bang' realisation is required with a figurehead victim that strikes an empathetic tone with the public. 
Such a sudden realisation is not associated with creeping problems, such as police handling of complaints of rape (HMIC 2014). In recent years there has been sporadic interest in the plight of complainants of sexual assault - including an officer's criticism of her own force in the treatment of her daughter (Warburton 2016), instances of abuse of power across the police in the sexual assault and exploitation of victims (Laville 2016), and a woman experiencing five years of delay including the suspect skipping bail while the relevant agencies failed to communicate effectively (Bowcott 2018). Many of these complaints included allegations that complainants were not believed - itself evident of a lack of victim relatability. Despite evidence of a systemic problem, a full public inquiry has yet to materialise, instead responses have included other non-statutory measures such as the Stern Review (2010) that examined the response of public authorities to complainants of rape, and the Payne Review that examined the experience of victims (2009). The problem is, however, ongoing. The Rape Monitoring Group (RMG), established in 2007 under the coordination of HMIC, for example, has collated yearly, regional data concerning this handling of alleged cases. The data recorded by the group indicates a steady increase in the number of transferred or 'cancelled' records (formerly 'no-crime') from 1657 in 2014/15 to 2645 in 2016/17 (RMG Dashboard 2018). Despite this, the focus for an inquiry has instead fallen around blameworthy behaviour such as mishandling of evidence, with Scotland Yard's Directorate of Professional Standards launching an inquiry into 33 cases. Although in its infancy, the drivers for this independent review appear to mimic the pattern of mechanisms explored above, with an 'unnamed' employee being suspended and misconduct placed at the heart of media reporting on the issue (e.g. Dearden 2018).

Second, this has a wider impact on 'wicked problems', or those issues that seep beyond the remit of just one organisation, and represent a broader matter of societal discontent. Previous studies have demonstrated such 'cross-cutting themes' (Sullivan and Skelcher 2002) in areas including global warming (Levin et al 2012), health inequalities (Blackman et al 2006) disproportionate representation in special education (McCall et al 2009), and child abuse (Devaney and Spratt 2009), and have suggested that attention should move beyond 'narrow, vertical, performance management systems' (Ferlie et al 2011). Placing these aforementioned trends of 'no crime' within a broader frame of normative institutionalism (Cooper 2016), overlooking meaningful inquiry into the actions of the police as just one organisation contributes to a harmful cultural understanding of sexual assault and risks chronic policy failure across this sector including rising levels of crime and courtroom attrition. 
Our analysis suggests that one of the mechanisms for public salience is the legibility of a culture of blameworthy behaviour, and that public salience is highest when cultural problems fit a methodologically individualist frame.

This poses a challenge: methodological individualism focuses fact-finding and responsibilityseeking on the question of whether an institution is organised in a way that encourages or facilitates wrongdoing caused by agents that knew or should have known better. Full statutory inquiries are well suited to address social problems that have such individualist causes. Juridical processes suit the forensic tracing of agentic misconduct and the culpability of the organisation(s) in fostering that behaviour. This, in turn, facilitates blame and the identification of regulations that might prevent future occurrences. Some issues, however, will be better addressed by other mechanisms - such as Royal Commissions or independent panels -better suited to policy challenges with complex histories that exceed a specific event (Norris and Shepheard, 2017: 12). Such unsuitability of statutory inquiries was illustrated in the Leveson Inquiry, in which participants repeatedly raised concerns about journalistic trivialisation and sexualisation of violence against women. Leveson concluded that his inquiry was not the place to address the "sociological factors" behind such pathological organisational behaviour, such as a "sense of impunity" held by some parts of the press due to their concentrated economic and social power. Leveson "doubt[ed] whether [the inquiry] would have had the expertise" to undertake such an analysis (Leveson, 2012: 719; see also O’Neill, 2013), reflecting existing arguments that the judicial process is often ill-suited to such matters (Schwartz 1997: 79).

The challenge identified by this paper is that non-individualist framings of cultural pathologies such as those based on structural relationships that exist within society more broadly - are less salient as blameworthy. A paradox ensues. Pathological organisational cultures are less likely to be publicly salient unless they fit an individualist frame, but that individualist framing may catapult a cultural problem into a statutory inquiry that is ill-suited to address the challenge comprehensively. For example, in the immediate wake of the Grenfell Tower fire the Prime Minister appointed a statutory inquiry. This inquiry is well suited to its terms of reference to investigate the immediate causes of the fire, decisions relating to the design and construction of the building, the suitability of safety regulations, and the actions of authorities on the night of, and prior to the fire. These terms of reference, however, do not easily accommodate wider questions about the role of race, 
religion and social class in the provision and maintenance of social housing. Where these issues have been raised, this has descended into a criticism that agents and authorities were intentionally and institutionally racist (Gadher, 2018). This unhelpful, and typically individualist interpretation reduces the matter to one of two explanations: either authorities knew they were acting wrongly or 'unwittingly' discriminated against some residents of Grenfell because of ignorance, a lack of understanding or training (see Wight 2003). This hinders a less sensationalist analysis of the wider context of inequality and social housing in Britain (McKee, 2017). In sum, the tendency of systemic issues to become salient in individualist terms has a limiting effect on the investigation of inequality.

\section{Conclusion}

Appointment of inquiry type is linked to issue salience. This paper provides a multi-dimensional understanding of issue salience. A productive scoping exercise across 'typical' cases studies has enabled the unpacking of this previously identified concept into three interwoven aspects; relatable victim, visibility of management failings and perceived institutional blameworthiness. This qualitative exercise has in turn suggested a set of causal mechanisms that form the fabric of the cause and effect that has long been assumed between issue salience and public inquiry. This has importantly led to a more discerning insight into the type of investigatory tool selected and highlighted a spectrum of public acceptance that corresponds to the selection of inquiries of increasing notoriety. Of empirical impact, however, the construction of salience in this manner can harmfully dismiss the reality of the institutional crisis at hand, creating a threshold that overlooks 'marginal' issues and/or endorsing an inquiry type that lacks the structural constituents and scope to address complex cultural matters. Accepting the infancy of the probing technique into causal mechanisms outlined in this paper, therefore, we encourage a new research agenda that expands the pool of analysis, and operational procedure, to further confirm or disconfirm our deconstruction of issue salience.

, and we encourage further 'large-n' research to test this framework.

\section{References}

Alberti, G. (2009), Mid Staffordshire NHS Foundation Trust: A review of the procedures for emergency admissions and treatment, and progress against the recommendation of the March Healthcare Commission report. Department of Health. 
Bentham, M. (2010), Family fury as police escape charges over Ian Tomlinson's G20 death. Evening Standard, $22^{\text {nd }}$ July.

Blackman, T, Greene, A., Hunter, D., McKee, L., Elliott, E., Harrington, B., Marks, L., and Williams., G. (2006), "Performance assessment and wicked problems: the case of health inequalities." Public Policy and Administration 21(2) 66-80.

Boin, A., 't Hart, P. and McConnell, A. (2009) Crisis exploitation: political and policy impacts of framing contests. Journal of European Public Policy, 16(1), pp.81-106.

Bovens, M. and 't Hart, P. (1996) Understanding Policy Fiascos. New Brunswick, NJ: Transaction.

Bowcott, O. (2018), "Woman abandons rape case in despair at legal process" The Guardian, $15^{\text {th }}$ February.

Brändström, A. and Kuipers, S. (2003) From 'normal incidents' to political crises: Understanding the selective politicization of policy failures. Government and opposition, 38(3), pp.279-305.

Brock, G., (2012), The Leveson Inquiry: There's a bargain to be struck over media freedom and regulation. Journalism, 13(4), pp.519-528.

Brown, A.D. (2004), 'Authoritative Sensemaking in a Public Inquiry Report'. Organisational Studies. 25 (1): 95-112.

Burgess, A., (2011), The changing character of public inquiries in the (risk) regulatory state. British Politics, 6(1), pp.3-29.

Cabinet Office (2012), Inquiries Guidance. Available at: https://www.parliament.uk/documents/lords-committees/Inquiries-Act2005/caboffguide.pdf

Calkin, S. (2011), "Whistleblowing Mid Staffs nurse too scared to walk to car after shift" Nursing Times, $17^{\text {th }}$ October.

Culture, Media and Sport Committee. (2010), Press standards, privacy and libel. London: The Stationery Office.

Culture, Media and Sport Committee (2012), News International and Phone Hacking. London: The Stationery Office.

Daoust P (ed) (2011), PhoneHacking: How the Guardian broke the story. Guardianshorts series, Guardian Books ebook.

Dearden, L. (2018), "Police launch urgent review into 'forensics mishandling' in rape and violence cases" The Independent, $8^{\text {th }}$ May.

Desmond, R. (2012) Transcript of Afternoon Hearing 12 January 2012. Available at: https://webarchive.nationalarchives.gov.uk/20140122152019/http://www.levesoninqui ry.org.uk/hearing/2012-01-12pm/ 
Devaney, Jo, and Spratt. T (2009), "Child abuse as a complex and wicked problem: Reflecting on policy developments in the United Kingdom in working with children and families with multiple problems." Children and Youth Services Review 31(6): 635-641.

Elliott, D. (2009) The Failure of Organization Learning from Crisis - A Matter of Life and Death? Journal of Contingencies and Crisis Management. 17 (3):157-168

Elliott, D. and McGuinness, M. (2002), Public inquiry: panacea or placebo?. Journal of Contingencies and Crisis Management, 10(1), pp.14-25.

Francis, R. (2010), Independent inquiry into care provided by mid Staffordshire NHS Foundation Trust January 2005-March 2009 (Vol. 1). The Stationery Office.

Francis, R. (2013), Report of the Mid Staffordshire NHS Foundation Trust public inquiry: executive summary (Vol. 947). The Stationery Office.

Gadher, D. (2018), Grenfell Tower fireman hits back at lawyer Imran Khan's racism 'slur'. The Times, $17^{\text {th }}$ June.

Gander, K. (2014) "NHS whistleblower Julie Bailey abused on Facebook after being awarded CBE" The Independent, $1^{\text {st }}$ January.

Greer, C. and McLaughlin, E. (2011), 'This is not Justice' Ian Tomlinson, Institutional Failure and the Press Politics of Outrage. The British Journal of Criminology, 52(2), pp.274-293.

Healthcare Commission. (2009), Investigation into mid Staffordshire NHS foundation trust. London: Healthcare Commission.

HMIC (2009), Adapting to Protest: Nurturing the British Model of Policing. London: Her Majesty's Inspectorate of Constabulary. https://www.independent.co.uk/news/uk/crime/met-police-forensics-mishandlingreview-rape-sexual-assault-violent-cases-a8342021.html

Hood, C (2010) The blame game: Spin, bureaucracy, and self-preservation in government. Princeton, NJ : Princeton University Press.

Hopkins, H. (2012), Nobody likes a rotten apple, but someone picks them. In Keeble R and Mair J (eds), The Phone Hacking Scandal. Bury St Edmunds: Abramis, pp 9-16.

Howlett, M., (2012) The lessons of failure: learning and blame avoidance in public policy-making. International Political Science Review, 33(5), pp.539-555.

King, G., Keohane, R., and Verba, S. (1994) Designing social inquiry: Scientific inference in qualitative research. Princeton, NJ : Princeton University Press.

Laville, S. (2016), “ The police are still ignoring sexual abuse by officers. It's time for zero tolerance" The Guardian, $8^{\text {th }}$ December. 
Leveson, B. (2012) An inquiry into the culture, practices and ethics of the press. London: The Stationery Office.

Levin, K., Cashore, B., Bernstein, S., and Auld,. (2012) "Overcoming the tragedy of super wicked problems: constraining our future selves to ameliorate global climate change." Policy sciences 45(2): 123-152.

Lewis, P. (2010), Blair Peach: After 31 years Met police say 'sorry' for their role in his killing, 27th April

Lewis, P. (2011), Ian Tomlinson unlawfully killed, inquest finds. The Guardian, $3^{\text {rd }}$ May

McCall, Z. and Skrtic, T. (2009), "Intersectional needs politics: A policy frame for the wicked problem of disproportionality." Multiple Voices for Ethnically Diverse Exceptional Learners 11(2): 3-23.

McKee, M. (2017), Grenfell Tower fire: why we cannot ignore the political determinants of health. BMJ: British Medical Journal (Online), 357.

Natta, D., Becker, J. and Bowley G. (2010) Tabloid Attack on Royals and Beyond. The New York Times. 1st September.

Norris, E., and Shepheard, M. (2017) How public inquiries can lead to change. Institute for Government. Available at: https://www.instituteforgovernment.org.uk/sites/default/files/publications/Public\%20Inquiries $\% 20 \% 28$ final $\% 29$.pdf

O’Neill, D. (2013), Will Leveson see off sexist coverage in the Press? In Mair, J (ed), After Leveson. Bury St Edmunds: Abramis, pp. 108-116.

O’Neill, S. (2010). G20 riot officer Delroy Smellie cleared of assault on Nicola Fisher. The Times, 1st April.

Payne, S. (2009), Rape: The victim experience review. London: Home Office.

Public Administration Select Committee, Government by Inquiry (London: The Stationery Office Ltd, 2005).

Roots, R. (2004) 'When laws backfire: Unintended consequences of public policy.' American Behavioral Scientist 47:11,1376-1394.

Schwartz, B. (1997) Public Inquiries. Canadian Public Administration. 40 (1):72-85.

Seawright, J. and Gerring. J. 2008. 'Case selection techniques in case study research: A menu of qualitative and quantitative options.' Political Research Quarterly 61(2): 294-308.

Sawer, P. (2009) Staffordshire hospital scandal: the hidden story. The Telegraph, $22^{\text {nd }}$ March. 
Smith, R. (2009), "NHS targets 'may have led to 1,200 deaths' in Mid-Staffordshire" The Telegraph, $18^{\text {th }}$ March.

Stark, A. 2018. Public Inquiries, Policy Learning, and the Threat of Future Crises. Oxford: Oxford University Press.

Stern, V. (2010), “A report by Baroness Vivien Stern CBE of an independent review into how rape complaints are handled by public authorities in England and Wales" The Stern Review.

Sulitzeanu-Kenan, R. (2006), If they get it right: An experimental test of the effects of the appointment and reports of UK public inquiries. Public Administration, 84(3): 623-653.

Sulitzeanu-Kenan, R. (2010), Reflection in the shadow of blame: When do politicians appoint commissions of inquiry?. British Journal of Political Science, 40(3), pp.613-634.

Sullivan, H. and Skelcher, C. (2002) Working across Boundaries - Collaboration in Public Services. Basingstoke: Palgrave Macmillan.

Templeton, S. (2013), "Hospital whistleblower hounded out of town” The Times, $25^{\text {th }}$ May.

Thomé, D. (2009), Mid Staffordshire NHS Foundation Trust: A review of lessons learnt for commissioners and performance managers following the Healthcare Commission investigation. London: Mid Staffordshire NHS Foundation Trust Public Inquiry.

Thomas, O (2017), Good faith and (dis)honest mistakes? Learning from Britain's Iraq War Inquiry. Politics 37(4): 371-385.

Veitch, S. (2007) Law and Irresponsibility: On the legitimation of human suffering. London and New York: Routledge.

Walker, P. (2012). Simon Harwood: 'I was wrong to hit and push Ian Tomlinson'. The Guardian, $3^{\text {rd }}$ July.

Walshe, K. and Higgins, J. (2002) The use and impact of inquiries in the NHS. BMJ: British Medical Journal, 325(7369): 895.

Warburton, D. (2016), “Top cop's fury at her own police force after daughter's rape case hell" The Mirror, $12^{\text {th }}$ November.

Wight, C. (2003) 'The agent-structure problem and institutional racism.' Political Studies 51: 706-21. 